\title{
Trend of Head and Neck Cancers in a National Tertiary Cancer Hospital of Nepal from 2012 to 2017
}

\author{
Gambhir Shrestha ${ }^{1}$ Bhola Siwakoti ${ }^{2}$ Rashmi Mulmi ${ }^{2}$ \\ ${ }^{1}$ Department of Community Medicine, Maharajgunj Medical \\ Campus, Institute of Medicine, Tribhuvan University, Maharajgunj, \\ Kathmandu, Nepal \\ 2Department of Cancer Prevention, Control and Research, B.P. \\ Koirala Memorial Cancer Hospital, Bharatpur, Chitwan, Nepa \\ ${ }^{3}$ ENT, Head and Neck Unit, Department of Surgical Oncology, B.P. \\ Koirala Memorial Cancer Hospital, Bharatpur, Chitwan, Nepal
}

\section{Dejkumar Gautam ${ }^{3}$}

Address for correspondence Gambhir Shrestha, MD, Department of Community Medicine, Maharajgunj Medical Campus, Institute of Medicine, Tribhuvan University, Maharajgunj, Kathmandu, Nepal (e-mail: gamvir.stha@gmail.com).

South Asian J Cancer 2021;10:236-240.

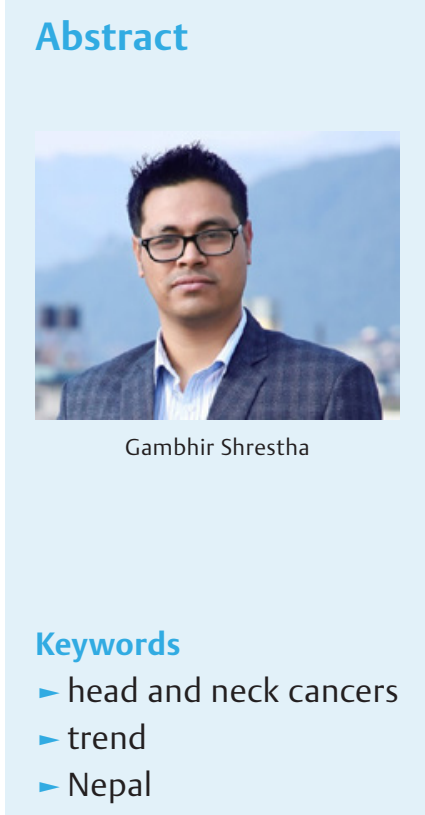

Introduction Head and neck cancers (HNCs) are increasing in Nepal and have become a major public health issue. This study aims to describe the trend of HNCs in a national tertiary cancer hospital in Nepal.

Methods This was a cross-sectional study with secondary data analysis conducted at B.P Koirala Memorial Hospital, Chitwan, Nepal. The data were obtained from the medical record section and included all new HNC cases registered from 2012 to 2017. Analysis was done using Statistical Package for Social Sciences version 17. Subgroup analysis was done according to age, gender, site, and year.

Results A total of 4,582 new HNCs were registered, of which 3,097 (67.6\%) were males and $1,482(32.4 \%)$ were females. Lip and oral cavity cancers $(46.5 \%)$ were the most common HNCs followed by tonsil and pharynx (18.0\%) and larynx (15.8\%). The trend of HNCs shows a steady rise in incidence with difference according to the sites. HNCs were more common among males than females except for thyroid cancer. The most common age group was 60 to 74 years.

Conclusions The trend of HNCs is increasing in Nepal especially oral cancers. Awareness of risk factors, effective screening programs, and comprehensive treatment should be focused to decrease the burden of HNCs.

\section{Introduction}

Cancer is a major public health problem in the world. It is one of the leading causes of death in Nepal. ${ }^{1}$ It is estimated that there were 26,184 new cancer cases in Nepal in 2018 with age-standardized incidence rate of 103.7 per 100,000 population. ${ }^{2}$ Further, it is estimated that the global incidence of new cancer cases will rise from 18.1 million cases

DOI https://doi.org/10.1055/s-0041-1731131 ISSN 2278-330X

How to cite this article: Shrestha G, Siwakoti B, Mulmi R, et al. Trend of Head and Neck Cancers in a National Tertiary Cancer Hospital of Nepal from 2012 to 2017. South Asian J Cancer 2021;10(4):236-240. in 2018 to 29.5 million by $20400^{3,4}$ Head and neck cancers (HNCs) are the sixth most common cancer worldwide and are defined as a heterogeneous group of malignant tumors of the airways and upper digestive system. ${ }^{5}$ These include malignancies of the oral cavity, nose, pharynx, larynx, paranasal sinuses, salivary glands, and thyroid. HNCs are a major issue in developing countries like ours, mainly due to the widespread use of tobacco and alcohol consumption. ${ }^{6,7}$ Usually,

(c) 2021. MedIntel Services Pvt Ltd.

This is an open access article published by Thieme under the terms of the Creative Commons Attribution-NonDerivative-NonCommercial-License, permitting copying and reproduction so long as the original work is given appropriate credit. Contents may not be used for commercial purposes, or adapted, remixed, transformed or built upon. (https://creativecommons.org/licenses/by-nc-nd/4.0/).

Thieme Medical and Scientific Publishers Private Ltd A-12, Second Floor, Sector -2, NOIDA -201301, India 
they are presented in the later stage in Nepal. ${ }^{8,9}$ The other risk factors are infection with human papilloma virus (HPV), poor oral hygiene, and poor diet. ${ }^{5}$ However, the risk factors for thyroid cancers differ and commonly occur in females and include radiation exposure, a diet low in iodine, and hormonal factors. ${ }^{10}$

It is important to know the trend of cancer over time for the effective planning and implementation of public health action and comprehensive management of cancer. Hence, the present study aims to describe the trend in distribution and incidence of HNCs by age, sex, and site in B.P Koirala Memorial Cancer Hospital (BPKMCH).

\section{Methods}

This was a cross-sectional study performed based on existing data, obtained from the medical record database of BPKMCH. BPKMCH is centrally located in Nepal at Bharatpur Metropolitan City of Chitwan District. It is the largest national tertiary cancer hospital, which receives majority of cancer patients from all over Nepal. This study included new HNC cases registered from 2012 to 2017. All patients diagnosed with HNCs were identified using site-specific International Classification of Diseases 10th version codes. Sites of HNCs reviewed in this study included: lip and oral cavity (CO0-06), major salivary glands (C07, 08), tonsil and pharynx (C09-14), nasal cavity and paranasal sinus $(\mathrm{C} 30,31)$, larynx (C32), and thyroid gland (C73). The data were retrieved in Microsoft Excel 2013, duplicates removed, and analyzed in Statistical Package for Social Sciences (SPSS) version 17. The number and percentage of cases were examined by gender, age, and tumor location. Male-to-female ratios were also calculated by different HNC sites. The trends of incidence of HNC by sites and year were demonstrated by line diagrams. Permission to use the data for this study was taken from the Research Committee of BPKMCH.

\section{Results}

A total of 27,908 new cancer cases were registered in BPКМCH from 2012 to 2017, out of which 45\% were males and 55\% were females. Similarly, 4,582 (16.4\%) of the total cases were
HNCs, of which 3,097 (67.6\%) were males and 1,482 (32.4\%) were females. Lip and oral cavity cancers (46.5\%) were the most common HNCs followed by tonsil and pharynx (18.0\%), larynx (15.8\%), thyroid (10\%), nasal cavity and paranasal sinuses (5.7\%), and major salivary glands (4.1\%). Among the total cancer cases, the male-female ratio was found to be 0.82 with females having a higher proportion (55.0\%). In contrast, HNCs were more common among men with a male-to-female ratio of 2.09. The male-to-female ratio was different according to sites of HNCs. The ratio was found to be more than 1 in all sites except for thyroid cancer. This depicts that all cancers of the head and neck region were more common among the males except for thyroid cancer. The highest ratio was found in tonsil and pharynx of 2.91 followed by lip and oral cavity of 2.80, and larynx of 2.65. Thyroid cancer was found to be more common among females (69.8\%) with a male-to-female ratio of 0.43 ( - Table 1 ).

Cancer cases were found to be more common in the age group of 45 to 59 years (32.6\%), 60 to 74 years (31.1\%), followed by 30 to 44 years (18.4\%). However, HNCs were common in the old age group of 60 to 74 years (37.0\%), followed by 45 to 59 years (32.7\%) and 30 to 44 years (16.3). Similar results were observed in different sites of HNCs according to age distribution (-Table 2 ).

The trends of HNCs according to the site are shown in -Figs. 1 to 7 . The trends looked different for different sites. Male cases were more in each year than the female cases, and this was true according to the sites also, except for the thyroid cancer. The total HNC cases increased in the year 2013, then decreased in 2014, then the number rose steadily in each consecutive year. The trend was similar for males and females separately ( $>$ Fig. 1 ).

Similarly, in lip and oral cancer cases, the number decreased in 2014 and there was a sharp rise in the number in 2015 and 2016. However, for female cases, the trend looked almost steady (-Fig. 2).

The trend for salivary gland is that there was a sharp rise in the number of the cases in 2013, then a decrease in the number of cases each year (-Fig. 3). A similar trend was observed for tonsil and pharynx cancers with a slight increase in the number of cases in 2017 ( - Fig. 4).

Table 1 Distribution of head and neck cancers by site and gender in a national tertiary cancer hospital of Nepal during 2012 to 2017

\begin{tabular}{|l|l|l|l|l|l|l|l|}
\hline \multirow{2}{*}{ Sites } & \multicolumn{2}{|c|}{ Male } & \multicolumn{2}{c|}{ Female } & \multicolumn{2}{c|}{ Total } \\
\cline { 2 - 8 } & $n$ & $\%$ & $n$ & $\%$ & $n$ & Female \\
\hline Lip and oral cavity & 1,571 & 73.7 & 561 & 26.3 & 2,132 & 46.5 & 2.80 \\
\hline Major salivary glands & 107 & 57.5 & 79 & 42.5 & 186 & 4.1 & 1.35 \\
\hline Tonsil and pharynx & 613 & 74.4 & 211 & 25.6 & 824 & 18.0 & 2.91 \\
\hline Nasal cavity and PNS & 143 & 55.2 & 116 & 44.8 & 259 & 5.7 & 1.23 \\
\hline Larynx & 527 & 72.8 & 199 & 27.5 & 724 & 15.8 & 2.65 \\
\hline Thyroid gland & 136 & 29.8 & 319 & 69.8 & 457 & 10.0 & 0.43 \\
\hline Total HNC cases & 3,097 & 67.6 & 1,485 & 32.4 & 4,582 & 100.0 & 2.09 \\
\hline Total cancer cases & 12,555 & 45.0 & 15,353 & 55.0 & 27,908 & 100.0 & 0.82 \\
\hline
\end{tabular}

Abbreviations: HNC, head and neck cancer; PNS, paranasal sinus. 


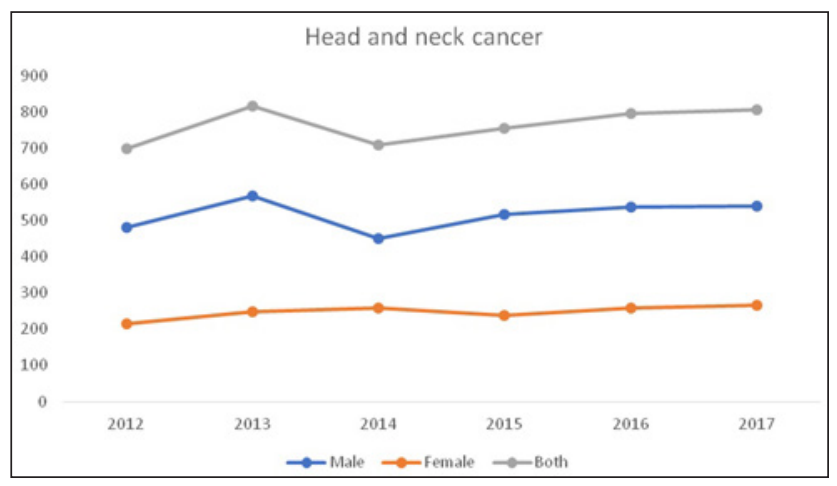

Fig. 1 The trend of head and neck cancers in a national tertiary cancer hospital of Nepal during 2012 to 2017.

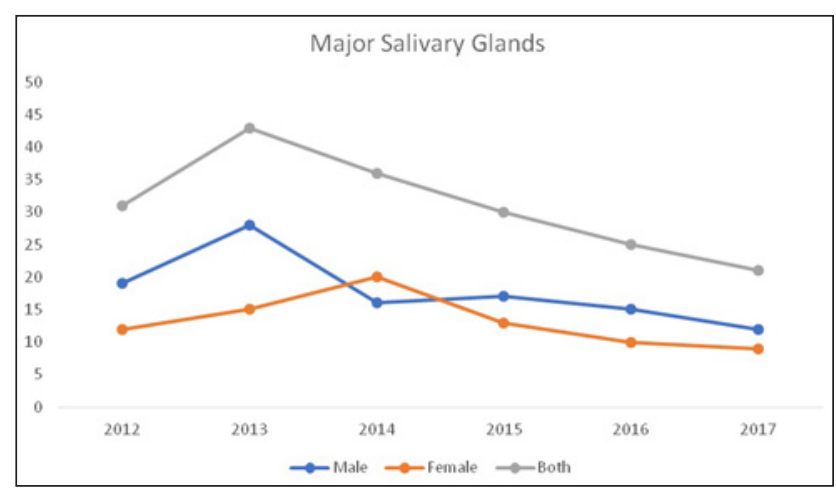

Fig. 3 The trend of cancers of major salivary glands in a national tertiary cancer hospital of Nepal during 2012 to 2017.

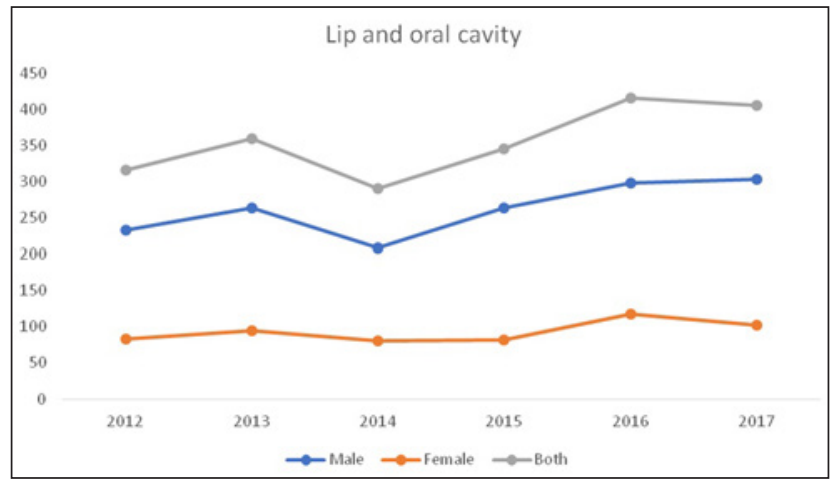

Fig. 2 The trend of cancers of lip and oral cavity in a national tertiary cancer hospital of Nepal during 2012 to 2017.

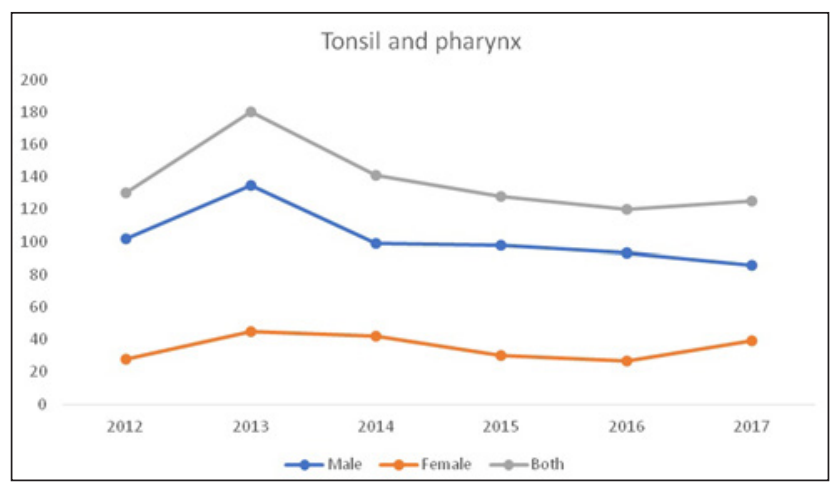

Fig. 4 The trend of cancers of tonsil and pharynx in a national tertiary cancer hospital of Nepal during 2012 to 2017.

Table 2 Distribution of head and neck cancers by site and age in a national tertiary cancer hospital of Nepal during 2012 to 2017

\begin{tabular}{|c|c|c|c|c|c|c|c|c|c|c|c|c|}
\hline \multirow[t]{2}{*}{ Sites } & \multicolumn{2}{|c|}{$0-14 y$} & \multicolumn{2}{|c|}{$15-29 y$} & \multicolumn{2}{|c|}{$30-44 y$} & \multicolumn{2}{|c|}{$45-59 y$} & \multicolumn{2}{|c|}{$60-74 y$} & \multicolumn{2}{|r|}{$\geq 75 y$} \\
\hline & $n$ & $\%$ & $n$ & $\%$ & $n$ & $\%$ & $n$ & $\%$ & $n$ & $\%$ & $n$ & $\%$ \\
\hline Lip and oral cavity & 17 & 0.8 & 57 & 2.7 & 405 & 19.0 & 757 & 35.5 & 773 & 36.3 & 123 & 5.8 \\
\hline Major salivary glands & 12 & 6.5 & 18 & 9.7 & 32 & 17.2 & 56 & 30.1 & 52 & 28.0 & 16 & 8.6 \\
\hline Tonsil and pharynx & 19 & 2.3 & 63 & 7.6 & 102 & 12.4 & 247 & 30.0 & 319 & 38.7 & 74 & 9.0 \\
\hline Nasal cavity and PNS & 5 & 1.9 & 21 & 8.1 & 44 & 17.0 & 81 & 31.3 & 88 & 34.0 & 20 & 7.7 \\
\hline Larynx & 3 & 0.4 & 4 & 0.6 & 37 & 5.1 & 247 & 34.1 & 353 & 48.7 & 80 & 11.0 \\
\hline Thyroid gland & 14 & 3.1 & 82 & 18.0 & 128 & 28.1 & 112 & 24.6 & 110 & 24.1 & 11 & 2.4 \\
\hline Total HNC cases & 70 & 1.5 & 245 & 5.3 & 748 & 16.3 & 1,500 & 32.7 & 1,695 & 37.0 & 324 & 7.1 \\
\hline Total cancer cases & 1,289 & 4.6 & 2,053 & 7.4 & 5,143 & 18.4 & 9,091 & 32.6 & 8,686 & 31.1 & 1,646 & 5.9 \\
\hline
\end{tabular}

Abbreviations: HNC, head and neck cancer; PNS, paranasal sinus.

There was a sharp rise in the cancers of nasal cavity and paranasal sinus (PNS) in 2013 and 2014 and an increase and a decrease in the consecutive years with the highest in the year 2016 ( - Fig. 5).

Laryngeal cancer in male cases looked steady with a slight decrease in 2014 and 2016. But the number was increased in the case of females till 2015 and a decrease in number was observed in 2016, then again an increase in 2017 ( - Fig. 6).

In contrast to other sites, thyroid cancer was observed more in females than in males each year. In total thyroid cancer, there was a decrease in the number of cases each year till 2016 and an increase in 2017. However, for the trend in cases of males and females separately, there was up and down in the number of cases by year ( - Fig. 7 ).

\section{Discussion}

Our data illustrate that there is a slight increase in the incidence of overall HNCs from 2012 to 2017. Our data also showed that the incidence of all HNCs for men is more than 


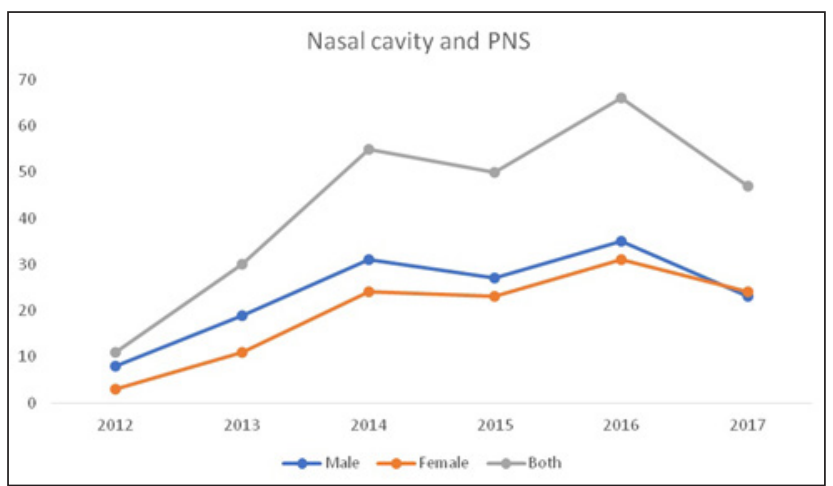

Fig. 5 The trend of cancers of nasal cavity and paranasal sinuses in a national tertiary cancer hospital of Nepal during 2012 to 2017.

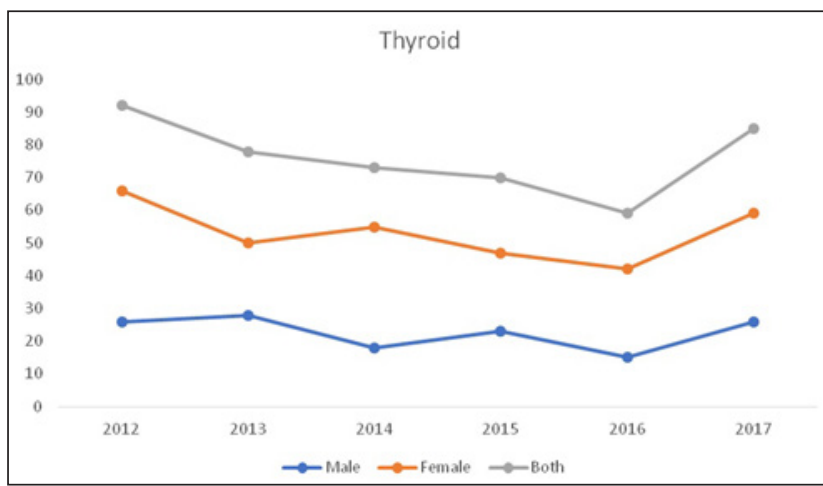

Fig. 7 The trend of thyroid cancers in a national tertiary cancer hospital of Nepal during 2012 to 2017.

that of women (male-to-female ratio: 1.23-2.91), except for thyroid cancer. This finding was similar to the findings of many other studies. ${ }^{11-13}$ It is a well-known fact that thyroid cancer is more common among women due to hormonal influence. ${ }^{10}$ Greater incidence of HNCs in Nepalese men can be due to the higher proportion of smokers among men than women ( $27.0 \mathrm{vs.} 10.3 \%$ ) and also higher proportion of smokeless tobacco use (men 31.3\% and women 4.8\%). ${ }^{14}$ Alcohol use is also another risk factor for HNCs. In Nepal, $28 \%$ of men and $7.1 \%$ of women are current alcohol drinkers. ${ }^{14}$ Alcohol and tobacco are consumed together in many parts of the country. This behavior acts synergistically as a risk for HNC. ${ }^{15,16}$ In addition to tobacco and alcohol, areca nut is widely consumed in Nepal mainly in the Terai region. Areca nut with or without tobacco is an established carcinogen and may result in oral submucosal fibrosis, a potentially premalignant condition and oral cancer. ${ }^{6}$ The role of HPV in the incidence of HNCs is not known exactly in Nepal. However, it is an established risk factor for HNCs. Unfortunately, HPV vaccination is not available in the national immunization program of the country. Another risk factor is poor oral hygiene; however, a nationally representative survey reported good oral hygiene in Nepal.

This study also showed that a huge proportion of cancer incidences is occupied by HNCs and oral cancer comprises a major proportion of the HNCs. Oral cancer can be easily screened and should have special consideration. ${ }^{17,18}$ There is an ongoing community-based screening of high-risk

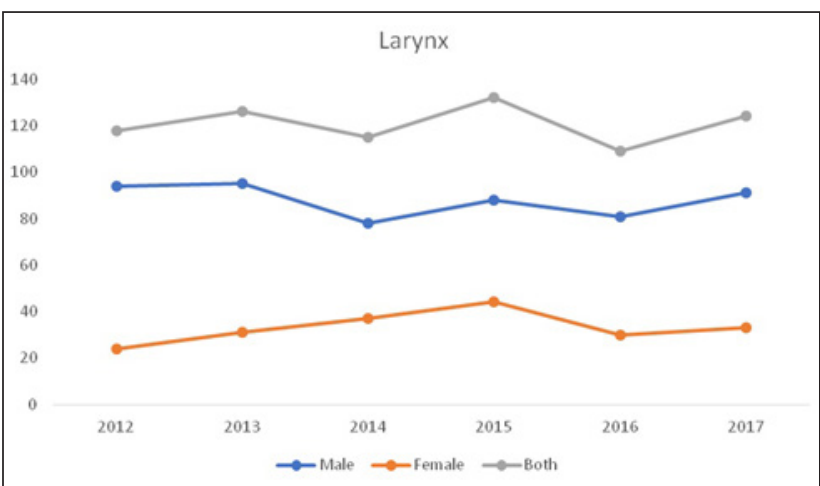

Fig. 6 The trend of laryngeal cancers in a national tertiary cancer hospital of Nepal during 2012 to 2017.

individuals for oral cancers in a different part of the country by BPKMCH. ${ }^{19}$ Although cancers arising from the nasal cavity and PNS are a rare entity, this study has shown a sharp rise in the incidence, which needs further evaluation.

Efforts should be made to reduce the burden of HNCs in Nepal. These involve raising awareness, screening, HPV vaccination, and proper implementation of tobacco and alcohol control policies along with encouraging health-seeking behavior to facilitate early diagnosis and treatment. ${ }^{20}$

The limitation of this study is that it cannot be generalized, as it includes only one hospital; however, BPKMCH is the largest comprehensive national cancer hospital in Nepal where the majority of the cancer cases from all over the country are diagnosed and treated.

\section{Conclusions}

The incidence of HNCs is increasing in Nepal with variation in trend by anatomical site and over time, with differences by sex. Among different types of HNCs, oral, nasal, and PNS cancers have shown the most rapid rise. Cancer in males is higher than in females for all types of HNCs, especially for cancer of the oral cavity, tonsil, and pharynx and larynx. Awareness and screening programs along with HPV vaccination should be implemented in the country with clear implications for public health action and service provision in Nepal.

\section{Conflict of Interest}

None declared.

\section{References}

1 Nepal Health Research Council, Ministry of Health and Population, Monitoring Evaluation and Operational Research, Nepal Burden of Disease 2017: A Country Report based on the Global Burden of Disease 2017 Study. Kathmandu, Nepal: NHRC, MoHP, and MEOR; 2019

2 GLOBOCAN. The Global Cancer Observatory: Nepal factsheet. International Agency for Research on Cancer, World Health Organization. 2018. Available at: http://gco.iarc.fr/today/data/ factsheets/populations/524-nepal-fact-sheets.pdf. Accessed July 1, 2019

3 GLOBOCAN. Global Cancer Observatory. International Agency for Research on Cancer, World Health Organization. 2018. Available at: https://gco.iarc.fr/tomorrow/home. Accessed July 1, 2019 
4 Bray F, Ferlay J, Soerjomataram I, Siegel RL, Torre LA, Jemal A. Global cancer statistics 2018: GLOBOCAN estimates of incidence and mortality worldwide for 36 cancers in 185 countries. CA Cancer J Clin 2018;68(6):394-424

5 Döbrossy L. Epidemiology of head and neck cancer: magnitude of the problem. Cancer Metastasis Rev 2005;24(1):9-17

6 Joshi P, Dutta S, Chaturvedi P, Nair S. Head and neck cancers in developing countries. Rambam Maimonides Med J 2014;5(2):e0009

7 Gupta B, Johnson NW, Kumar N. Global epidemiology of head and neck cancers: a continuing challenge. Oncology 2016;91(1):13-23

8 Chettri ST, Bhandary S, Singh RK, et al. Pattern of head and neck malignancies in eastern part of Nepal. Nepal Med Coll J 2013;15(1):34-36

9 Pokharel M, Shrestha I, Dhakal A, Amatya RCM. Socio demographic predictors in delayed presentation of head and neck cancer. Kathmandu Univ Med J (KUMJ) 2016;14(55):274-278

10 Dal Maso L, Bosetti C, La Vecchia C, Franceschi S. Risk factors for thyroid cancer: an epidemiological review focused on nutritional factors. Cancer Causes Control 2009;20(1):75-86

11 Bhurgri Y, Bhurgri A, Usman A, et al. Epidemiological review of head and neck cancers in Karachi. Asian Pac J Cancer Prev 2006;7(2):195-200

12 Dandekar M, Tuljapurkar V, Dhar H, Panwar A, DCruz AK. Head and neck cancers in India. J Surg Oncol 2017;115(5):555-563

13 Suh JD, Cho JH. Trends in head and neck cancer in South Korea between 1999 and 2012. Clin Exp Otorhinolaryngol 2016;9(3):263-269
14 Aryal KK, Mehata S, Neupane S, et al. The burden and determinants of non communicable diseases risk factors in Nepal: findings from a nationwide STEPS survey. PLoS One 2015;10(8):e0134834

15 Peters ES, McClean MD, Marsit CJ, Luckett B, Kelsey KT. Glutathione S-transferase polymorphisms and the synergy of alcohol and tobacco in oral, pharyngeal, and laryngeal carcinoma. Cancer Epidemiol Biomarkers Prev 2006;15(11):2196-2202

16 Maier H, Dietz A, Gewelke U, Heller WD, Weidauer H. Tobacco and alcohol and the risk of head and neck cancer. Clin Investig 1992;70(3-4):320-327

17 Fedele S. Diagnostic aids in the screening of oral cancer. Head Neck Oncol 2009;1:5

18 Sankaranarayanan $\mathrm{R}$, Ramadas $\mathrm{K}$, Amarasinghe $\mathrm{H}$, Subramanian S, Johnson N, Oral cancer: prevention, early detection, and treatment. In: Gelband H, Jha P, Sankaranarayanan R, et al., eds. Cancer: Disease Control Priorities, 3rd ed. (Vol. 3). Washington, DC: The International Bank for Reconstruction and Development/The World Bank; 2015 ;85

19 B.P. Koirala Memorial Cancer Hospital. BPKMCH Annual Report 2017. Chitwan, Nepal; 2018. Available at: www.bpkmch.org.np. Accessed March 22, 2019

20 World Health Organization, Cancer control: knowledge into action. WHO guide for effective programmes: prevention. Geneva: World Health Organization; 2007 